\title{
GAMBARAN FUNGSI KOGNITIF PADA LANSIA DI TIGA YAYASAN MANULA DI KECAMATAN KAWANGKOAN
}

\author{
${ }^{1}$ Daniar Aprilia Ramadian \\ ${ }^{2}$ Junita Maja P.S \\ ${ }^{3}$ Theresia Runtuwene
}

\author{
Bagian Neurologi Fakultas Kedokteran Universitas Sam Ratulangi Manado \\ Email: niar fku09@yahoo.co.id
}

\begin{abstract}
Background: An increasing number of elderly people raises various social, economic, and health problems. Health problems are often occur in the elderly is impaired cognitive function. The rapid examination and practical, high value is the examination of the Mini Mental State Examination (MMSE) and Trail Making Test (TMT). These checks are done by giving series of commands at someone and assess their accuracy.

Objective: To knowing overview of cognitive function in the elderly at three elderly people foundation in district Kawangkoan by sex, age, and education.

Methods: The descriptive research with cross-sectional method, was conducted in November 2012 held at the Elderly Foundation Centre Kawangkoan Minahasa, Maupusan Foundation, and Pakakamangen Foundation in District Kawangkoan.

Results: From the research gained 61 people who met the inclusion criteria consisted of 4 men and 57 women. Based on age, and education level showed decline in cognitive function is most at 75-90 years old and last education level is Elementary School.

Conclusion: The results of the MMSE and TMT in the elderly at three elderly people foundation in district Kawangkoan mostly with normal results on the MMSE and TMT abnormal.
\end{abstract}

Keywords: Elderly, cognitive function, MMSE, TMT-A \& B.

\begin{abstract}
Abstrak
Latar belakang: Peningkatan jumlah penduduk lanjut usia menimbulkan berbagai masalah sosial, ekonomi, dan kesehatan. Masalah kesehatan yang sering terjadi pada usia lanjut ialah gangguan fungsi kognitif. Pemeriksaan yang cepat dan praktis namun nilainya tinggi adalah pemeriksaan Mini Mental State Examination (MMSE) dan Trail Making Test (TMT). Pemeriksaan ini dilakukan dengan memberi serangkaian perintah pada seseorang dan menilai ketepatannya.

Tujuan: Untuk mengetahui gambaran fungsi kognitif pada lansia di tiga yayasan manula di kecamatan kawangkoan berdasarkan jenis kelamin, umur, dan pendidikan.

Metode: Penelitian deskriptif dengan metode potong lintang, dilaksanakan pada bulan November 2012 bertempat di Yayasan Manula Pusat Kawangkoan Minahasa, Yayasan Maupusan, dan Yayasan Pakakamangen di Kecamatan Kawangkoan.
\end{abstract}


Hasil: Dari penelitian diperoleh 61 orang yang memenuhi kriteria inklusi terdiri dari 4 laki-laki dan 57 perempuan. Berdasarkan usia, dan tingkat pendidikan menunjukkan penurunan fungsi kognitif terbanyak adalah pada usia 75-90 tahun dan tingkat pendidikan terakhir SD.

Kesimpulan: Hasil pemeriksaan MMSE dan TMT pada lansia di tiga yayasan manula di kecamatan Kawangkoan sebagian besar dengan hasil normal pada MMSE dan abnormal pada TMT.

Kata kunci: Lansia, fungsi kognitif, MMSE, TMT-A \& B.

Indonesia termasuk negara yang memasuki era penduduk berstruktur lanjut usia karena dari tahun ke tahun jumlah penduduk Indonesia yang berusia 60 tahun ke atas semakin meningkat. ${ }^{1}$ Menurut United Nation (UN)-Population Division, Departement of Economic and Social Affairs (1999) jumlah populasi lanjut usia (Lansia) $\geq 60$ tahun diperkirakan hampir mencapai 600 juta orang dan diproyeksikan menjadi dua milyar pada tahun $2050 .^{2}$

Pengertian lanjut usia menurut UU No. 13 tahun 1998 tentang kesejahteraan lansia menyatakan bahwa lansia adalah seseorang yang mencapai usia 60 tahun ke atas. Sedangkan WHO (1999) menggolongkan lanjut usia berdasarkan usia kronologis/biologis menjadi empat kelompok yaitu: usia pertengahan (middlelyoung elderly) berusia antara 45-59 tahun, lanjut usia (elderly) berusia antara 60-74 tahun, usia tua (old) berusia antara $75-90 .^{2,3}$

Peningkatan jumlah penduduk lanjut usia ini menimbulkan berbagai masalah sosial, ekonomi, dan kesehatan. Beberapa masalah kesehatan yang sering terjadi pada usia lanjut antara lain gangguan fungsi kognitif dan keseimbangan. ${ }^{4,5}$ Berdasarkan penelitian yang dilakukkan oleh Baltes, dkk (Santrock, 2000) ditemukan bahwa kecepatan memperoses informasi mengalami penurunan pada masa lanjut usia. ${ }^{6}$

Fungsi kognitif tersebut merupakan hasil interaksi dengan lingkungan yang di dapat secara formal dari pendidikan maupun non formal dari kehidupan sehari-hari. Gangguan satu atau lebih fungsi tersebut dapat menyebabkan gangguan fungsi sosial, pekerjaan, dan aktivitas harian. ${ }^{4}$ Berdasarkan pada penelitian yang dilakukan di Manado menemukan bahwa lansia yang mengalami gangguan kognitif sebesar 93,6\% (Ramdhani, 2012). ${ }^{7}$

Kemampuan berpikir ini dapat di periksa dengan berbagai pemeriksaan. Pemeriksaan yang cepat dan praktis namun nilainya tinggi adalah pemeriksaan Mini Mental State Examination (MMSE) dan Trail Making Test (TMT). Pemeriksaan ini dilakukan dengan memberi serangkaian perintah pada seseorang dan menilai ketepatannya. ${ }^{4}$

Berdasarkan uraian di atas tersebut, mendorong peneliti untuk mengetahui bagaimana gambaran fungsi kognitif di tiga yayasan manula di kecamatan kawangkoan. Tujuan penelitian untuk mengetahui gambaran fungsi kognitif pada lansia di tiga yayasan manula di Kecamatan Kawangkoan berdasarkan jenis kelamin, umur, dan pendidikan.

\section{METODE PENELITIAN}

Bentuk penelitian ini adalah deskriptif, dengan menggunakan 
metode cross sectional (potong lintang). Penelitian dilaksanakan pada bulan November 2012 bertempat di Yayasan Manula Pusat Kawangkoan Minahasa, Yayasan Maupusan, dan Yayasan Pakakamangen di Kecamatan Kawangkoan. Populasi penelitian seluruh lansia yang terdaftar di Yayasan Manula Pusat Kawangkoan Minahasa, Yayasan Maupusan, Yayasan Pakakamangen di Kecamatan Kawangkoan. Sedangkan sampel penelitian yang digunakan adalah lansia dengan kriteria kelompok umur usia $\geq 60$ tahun di Yayasan Manula Pusat Kawangkoan Minahasa, Yayasan Maupusan, Yayasan Pakakamangen di Kecamatan Kawangkoan. Sampel yang memenuhi kriteria dalam penelitian ini ialah yang berusia $\geq 60$ tahun, bersedia mengikuti penelitian, dan dapat berkomunikasi dengan baik. Dalam penelitian ini variabel yang akan di teliti: Jenis Kelamin (laki-laki dan perempuan), usia (menurut WHO 1999: ${ }^{3}$ lanjut usia/ elderly 60-74 tahun, usia tua/ old 7590 tahun, usia sangat tua/ very old $\geq$ 90 tahun), pendidikan (tidak sekolah, SD, SMP, SMA, perguruan tinggi), skor MMSE (menurut Assesment Scale in Old Age Psychiatry: ${ }^{8}$ nilai 24-30 normal, nilai 17-23 probable gangguan, nilai 0-16 defenitif gangguan kognitif), skor TMT-A (abnormal bila subyek menyelesaikan tugas dalam waktu > 55 detik atau tidak dapat menyelesaikan tugas), skor TMT-B (abnormal bila subyek dapat menyelesaikan dalam waktu >180 detik atau tidak dapat menyelesaikan tugas. Penulis melakukkan survei dan pendataan jumlah lansia di Yayasan Manula Pusat Kawangkoan Minahasa, Yayasan Maupusan, Yayasan Pakakamangen di Kecamatan Kawangkoan, kemudian di beri penjelasan tentang tujuan dan manfaat penelitian, subyek yang setuju di minta untuk menandatangani lembar persetujuan penelitian, selanjutnya dilakukan pengisian formulir penelitian, setelah itu dilakukan pemeriksaan MMSE dilanjutkan dengan pemeriksaan TMT-A dan TMT-B untuk menilai fungsi kognitif, hasil data yang di peroleh kemudian di analisis dan tampilkan dalam bentuk tabel.

\section{HASIL}

\section{Karakteristik Demografik.}

Didapatkan data jumlah total sampel pada penelitian ini adalah 65 orang. Namun dari 65 orang tersebut yang memenuhi kriteria inklusi hanya 61 orang, sedangkan 4 orang lainnya di eksklusi. Sampel terdiri dari 4 laki-laki $(6,6 \%)$ dan 57 perempuan $(93,4 \%)$. Sebagian besar sampel berada dalam kelompok usia 75-90 tahun (31 orang 50,8\%) dan dalam kelompok pendidikan SD (44 orang $72,4 \%$ ). Sebaran karakteristik demografik diperlihatkan pada Tabel 1. 
Tabel 1. Sebaran Subyek Penelitian Menurut Karakteristik Demiografik

\begin{tabular}{ccc}
\hline Karakteristik Demografi & Jumlah (n) & Persentase (\%) \\
\hline Jenis kelamin & & \\
• Laki-laki & 4 & 6,6 \\
• Perempuan & 57 & 93,4 \\
Usia & & \\
- $\quad 60-74$ & 30 & 49,2 \\
- $75-90$ & 31 & 50,8 \\
• $\geq 90$ & - & - \\
Pendidikan & 2 & 3,3 \\
- Tidak sekolah & 44 & 72,1 \\
- SD & 4 & 6,6 \\
- SMP & 9 & 14,8 \\
- SMA & 2 & 3,3 \\
- Perguruan tinggi & &
\end{tabular}

\section{Gangguan Fungsi Kognitif.}

Dengan menggunakan MMSE terdapat 2 orang $(3,3 \%)$ sampel yang mengalami gangguan kognitif. Namun demikin, saat mereka di uji dengan menggunakan TMT-A dan
TMT-B, jumlah sampel yang mengalami gangguan kognitif pada pemeriksaan TMT-A terdapat 58 orang $(95,1 \%)$ dan pada TMT-B terdapat 45 orang $(73,8 \%)$. Hasil pemeriksaan MMSE dan TMT diperlihatkan pada Tabel 2.

Tabel 2. Hasil Pemeriksaan Fungsi Kognitif

\begin{tabular}{ccc}
\hline \multicolumn{1}{c}{ Pemeriksaan } & Jumlah (n) & Persentase (\%) \\
\hline MMSE & & \\
• Normal & 44 & 72,1 \\
- Probable gangguan kognitif & 15 & 24,6 \\
• Definitif gangguan kognitif & 2 & 3,3 \\
TMT-A & 3 & \\
- Normal & 58 & 4,9 \\
• Terganggu & & 95,1 \\
TMT-B & 16 & 26,2 \\
• Normal & 45 & 73,8 \\
- Terganggu & &
\end{tabular}

Berikut ini adalah tabel hasil pemeriksaan MMSE dan TMT pada penelitian ini dengan berdasarkan jenis kelamin, usia, dan pendidikan. 
Tabel 3. Hasil Pemeriksaan MMSE Dengan Berdasarkan Jenis Kelamin, Usia, Pendidikan

\begin{tabular}{|c|c|c|c|c|c|c|}
\hline \multirow[b]{3}{*}{ Faktor Penentu } & \multicolumn{6}{|c|}{ MMSE } \\
\hline & \multicolumn{2}{|c|}{ Normal } & \multicolumn{2}{|c|}{ Probable } & \multicolumn{2}{|c|}{ Definitif } \\
\hline & $n$ & $\%$ & $\mathrm{n}$ & $\%$ & $\mathrm{n}$ & $\%$ \\
\hline \multicolumn{7}{|l|}{ Jenis Kelamin } \\
\hline - Laki-laki & 3 & 75 & 1 & 25 & - & - \\
\hline - Perempuan & 41 & 71,9 & 14 & 24,6 & 2 & 3,5 \\
\hline \multicolumn{7}{|l|}{ Usia } \\
\hline - $60-74$ & 26 & 86,7 & 4 & 13,3 & - & - \\
\hline - $75-90$ & 18 & 58 & 11 & 35,5 & 2 & 6,5 \\
\hline - $\quad \geq 90$ & - & - & - & - & - & - \\
\hline \multicolumn{7}{|l|}{ Pendidikan } \\
\hline - Tidak sekolah & 1 & 50 & 1 & 50 & - & - \\
\hline - $\mathrm{SD}$ & 29 & 65,9 & 13 & 29,6 & 2 & 4,5 \\
\hline - SMP & 3 & 75 & 1 & 25 & - & - \\
\hline - SMA & 9 & 100 & - & - & - & - \\
\hline - Perguruan Tinggi & 2 & 100 & - & - & - & - \\
\hline $\begin{array}{l}\text { Berdasarkan Tabel } \\
\text { bat kita lihat bahwa ju } \\
\text { dasarkan jenis kelamir } \\
\text { lah pada perempuan } \\
\text { ang }(71,9 \% \text { norma } \\
\text { bable, dan } 3,5 \% \\
\text { langkan laki-laki hany }\end{array}$ & $\begin{array}{r}\text { atas } \\
\text { ansia } \\
\text { nyak } \\
57 \\
4,6 \% \\
\text { nitif) } \\
\text { rang }\end{array}$ & \multicolumn{5}{|c|}{$\begin{array}{l}\text { ( } 75 \% \text { normal, dan } 25 \% \text { probable), } \\
\text { berdasarkan kelompok usia } \\
\text { terbanyak adalah pada usia } 75-90 \\
\text { tahun yaitu } 31 \text { orang ( } 58 \% \text { normal, } \\
35,5 \% \text { probable, } 6,5 \% \text { definitif), dan } \\
\text { berdasarkan tingkat pendidikan } \\
\text { terbanyak adalah pada tingkat SD } \\
\text { yaitu } 44 \text { orang }(65,9 \% \text { normal, } \\
29,6 \% \text { probable, } 4,5 \% \text { definitif. }\end{array}$} \\
\hline
\end{tabular}

Tabel 4. Hasil Pemeriksaan TMT-A dan TMT-B Dengan Berdasarkan Jenis Kelamin, Usia, Pendidikan

\begin{tabular}{lcccccccc}
\hline & \multicolumn{4}{c}{ TMT-A } & \multicolumn{5}{c}{ TMT-B } \\
\cline { 2 - 9 } & \multicolumn{3}{c}{ Normal } & \multicolumn{1}{c}{ Terganggu } & \multicolumn{1}{c}{ Normal } & \multicolumn{1}{c}{ Terganggu } \\
\cline { 2 - 9 } \multicolumn{1}{c}{ Faktor Penentu } & $\mathrm{n}$ & $\%$ & $\mathrm{~N}$ & $\%$ & $\mathrm{n}$ & $\%$ & $\mathrm{n}$ & $\%$ \\
\hline Jenis Kelamin & & & & & & & & \\
- Laki-laki & - & - & 4 & 100 & - & - & 4 & 100 \\
- Perempuan & 3 & 5,3 & 54 & 94,7 & 16 & 28,1 & 41 & 71,9 \\
Usia & & & & & & & & \\
- $\quad 60-74$ & 3 & 10 & 27 & 90 & 11 & 36,7 & 19 & 63,3 \\
- $75-90$ & - & - & 31 & 100 & 5 & 16 & 26 & 84 \\
- $\geq 90$ & - & - & - & - & - & - & - & - \\
Pendidikan & & & & & & & & \\
- Tidak sekolah & - & - & 2 & 100 & - & - & 2 & 100 \\
- SD & - & - & 44 & 100 & 6 & 13,6 & 38 & 86,4 \\
- SMP & 1 & 25 & 3 & 75 & 1 & 25 & 3 & 75 \\
- SMA & 2 & 22,2 & 7 & 77,8 & 8 & 88,9 & 1 & 11,1 \\
- Perguruan & - & - & 2 & 100 & 1 & 50 & 1 & 50 \\
$\quad$ tinggi & & & & & & & & \\
\hline
\end{tabular}


Berdasarkan Tabel 4 di atas dapat kita lihat bahwa jumlah lansia berdasarkan jenis kelamin terbanyak adalah perempuan yaitu 57 orang ( 5,3\% normal, $94,7 \%$ terganggu pada TMT-A dan $28,1 \%$ normal, $71,9 \%$ terganggu pada TMT-B), berdasarkan kelompok usia terbanyak adalah pada usia 75-90 tahun yaitu 31 orang $(100 \%$ terganggu pada TMT-A dan 16\% normal, $84 \%$ terganggu pada TMTB)., dan berdasarkan tingkat pendidikan terbanyak adalah pada tingkat SD yaitu 44 orang $(100 \%$ terganggu pada TMT-A dan $13,6 \%$ normal, $86,4 \%$ terganggu pada TMTB).

\section{PEMBAHASAN}

\section{Karakteristik Demografik}

Penelitian ini dilakukkan di tiga yayasan manula di kecamatan kawangkoan, yakni di Yayasan Manula Pusat Kawangkoan Minahasa, Yayasan Maupusan, dan Yayasan Pakakamangen di Kecamatan Kawangkoan, dengan jumlah lansia seluruhnya 65 orang, namun pada penelitian ini hanya 61 orang yang memenuhi kriteria inklusi. Adapun faktor eksklusi di tiga yayasan manula di atas yakni, tidak mampu melakukkan kegiatan, seperti tidak mampu menulis, membaca, dan menggambar, yang dikarenakan rabun, dan juga penurunan fungsi pendengaran.

Dari ke tiga yayasan manula di kecamatan Kawangkoan menunjukkan bahwa jumlah perempuan $(93,4 \%)$ lebih banyak dibandingkan laki-laki $(6,6 \%)$. Hasil ini mirip dengan suatu penelitian pada lansia di Jakarta yang memberi hasil persentase perempuan $75 \%$ (Hesti dkk, 2008). Dikarenakan cara pengambilan data langsung mendatangi pusat kesehatan atau panti werdha. ${ }^{4}$

Penelitian ini membagi lansia menjadi tiga kelompok usia yaitu 6074 tahun, 75-90 tahun, dan di atas 90 tahun. Kelompok usia yang paling banyak adalah 75-90 tahun yaitu sebanyak 31 orang $(50,8 \%)$. Pengelompokan ini serupa dengan penelitian Hesti dkk dengan batas minimum 60 tahun. ${ }^{4}$

Tingkat pendidikan pada penelitian ini di bagi menjadi tidak sekolah, SD, SMP, SMA, dan perguruan tinggi. Tingkat pendidikan yang paling banyak adalah SD yaitu sebanyak 44 orang $(72,1 \%)$. Hal ini mirip dengan penelitian yang dilakukan oleh Ramdhani (2012), bahwa tingkat pendidikan yang paling banyak yaitu $\leq 9$ tahun sebanyak 32 orang $(68,1 \%)$. Rendahnya tingkat pendidikan salah satu indikator masih rendahnya kualitas hidup lansia. $^{7}$

\section{Gangguan fungsi kognitif.}

Untuk menilai fungsi kognitif pada penelitian ini dilakukan dengan dua pemeriksaan yaitu MMSE dan TMT. Dengan MMSE didapatkan $24,6 \%$ kemungkinan terganggu dan $3,3 \%$ terganggu, sedangkan dengan TMT didapatkan angka yang lebih besar yaitu untuk TMT-A sebesar 95,1\% dan TMT-B sebesar 73,8\%. Hal ini mirip dengan penelitian yang dilakukan oleh Ramdhani (2012). Perbedaan hasil MMSE dan TMT mungkin disebabkan karena sebagian besar tugas pada MMSE hanya diberikkan secara lisan dan tidak membutuhkan kecepatan. Sedangkan pada TMT diberikan tugas terkait waktu yang membutuhkan Berdasarkan jenis kelamin dapat telihat bahwa gangguan fungsi kognitif banyak dialami oleh 
perempuan yaitu pada MMSE $(24,6 \%)$ kemungkinan terganggu dan $(3,5 \%)$ terganggu, dan pada TMT-A $(94,7 \%)$ terganggu dan TMT-B $(71,9 \%)$ terganggu. Namun pada penelitian oleh Tombaugh (2003) dan Ashendorf, dkk (2007) tidak menemukan adanya hubungan antara jenis kelamin pada pemeriksaan TMT. ${ }^{10,11}$ Perbedaan yang terjadi pada penelitian ini dikarenakan tidak seimbangnya jumlah sampel antara laki-laki dan perempuan.

Pada pemeriksaan MMSE dan TMT berdasarkan kelompok umur di tiga yayasan manula di kecamatan Kawangkoan menunjukkan penurunan fungsi kognitif terbanyak pada umur 75-90 tahun. Hal ini serupa dengan penelitian yang dilakukan oleh Tombaugh (2003) yang menyatakan bahwa semakin meningkatnya umur maka semakin menurun pula hasil pemeriksaan. ${ }^{11}$

Pada pemeriksaan MMSE dan TMT berdasarkan tingkat pendidikan di tiga yayasan manula di kecamatan Kawangkoan menunjukkan hasil penurunan fungsi kognitif terbanyak pada tingkat pendidikan lulusan SD. Hal ini serupa dengan penelitian yang dilakukan oleh Lopez dkk di kutuip oleh Ramdhani (2012) yang menyatakan tingkat pendidikan rendah merupakan salah satu prediktor terjadinya gangguan kognitif. ${ }^{7}$

Tingginya persentase gangguan kognitif pada penelitian ini kemungkinan disebabkan karena konsep kriteria gangguan kognitif yang harus memenuhi tes MMSE dan TMT. Dalam penelitian ini, terlihat bahwa TMT lebih sensitif dibandingkan MMSE dalam mendeteksi gangguan fungsi kognitif pada lansia di tiga yayasan manula di kecamatan Kawangkoan.

\section{SIMPULAN}

1. Hasil pemeriksaan MMSE pada lansia di 3 yayasan manula di kecamatan Kawangkoan sebagian besar dengan hasil normal yakni $72,1 \%$.

2. Hasil pemeriksaan TMT-A dan TMT-B pada lansia di 3 yayasan manula di kecamatan Kawangkoan sebagian besar dengan hasil terganggu yakni 95.1\% pada TMT-A dan $73,8 \%$ pada TMT-B.

3. Hasil pemeriksaan MMSE dan TMT pada lansia di 3 yayasan manula di kecamatan Kawangkoan berdasarkan usia, dan tingkat pendidikan menunjukkan penurunan fungsi kognitif terbanyak adalah pada usia 75-90 tahun dan tingkat pendidikan terakhir SD.

\section{SARAN}

1. Deteksi yang lengkap pada lansia khususnya di panti-panti werdha.

2. Penyusunan program asuhan lansia di yayasan manula dan panti werdha perlu memperhatikan aspek pemeliharaan fungsi kognitif.

3. Perlu dilakukan penelitian lanjutan dengan populasi lansia di Sulawesi Utara dengan disain yang lebih baik.

4. Pada penelitian selanjutnya agar dapat melakukan anamnesis dan pemeriksaan fisik yang lebih lengkap.

5. Perlu dilakukkan kegiatankegiatan untuk merangsang fungsi kognitif pada lansia seperti ibadah bersama, kegiatan kerajinan tangan, olahraga, dll.

6. Perlu diadakan penyuluhan mengenai pendidikan wajib 9 
tahun pada masyarakat, agar di peroleh fungsi kognitif yang lebih baik.

\section{UCAPAN TERIMA KASIH}

Terima kasih kepada dr. Arthur H. P. Mawuntu, SpS selaku penguji I dan dr. Danny J. Ngantung, SpS selaku penguji II dan semua pihak yang secara langsung dan tidak langsung telah menumbuhkan ide atau gagasan sehingga penulis dapat menyelesaikan tulisan ini.

\section{DAFTAR PUSTAKA}

1. Saputri MAW, Indrawati ES. Hubungan Antara Dukungan Sosial Dengan Depresi Pada Lanjut Usia Yang Tinggal Di Panti Werda Wening Wardoyo Jawa Tengah. Jurnal Psikologi Undip. 2011;9:65.

2. Darmojo RB. Demografi dan Epidemiologi Populasi Lanjut Usia. Dalam: Martono $\mathrm{HH}$, Pranarka K. Buku Ajar BoedhiDarmojo Geriatri. Edisi ke-4. Jakarta: Balai Penerbit FKUI;2010.h. 35-55.

3. Azizah LM. Keperawatan lanjut usia. Ed 1. Yogyakarta: Graha Ilmu; 2011.h. 1-17.

4. Hesti, Harris S, Mayza A, Prihartono J. Pengaruh Gangguan Kognitif Terhadap Gangguan Keseimbangan Pada Lanjut Usia. Neurona.2008;25:26-31.

5. Setiati S, Harimurti K, R Arya G. Proses menua dan implikasi kliniknya. Dalam: Sudabyo AW, Setiyohadi B, Alwi I, Simadibrata M, Setiati S. Buku ajar ilmu penyakit dalam. Ed 5 .
Jilid I. Jakarta: Pusat Penerbitan Departemen IPD FKUI; 2009.h. 757-60.

6. Kusumiati RYE. Tinggal Sendiri Di Masa Lanjut Usia. Humanitas. 2009;6:27.

7. Ramdhani N. Gambaran Fungsi Kognitif Dan Keseimbangan Pada Lansia Di Kota Manado. KTIS. Manado: FK UNSRAT 2012:h.19:39-41.

8. Burns AS, Lawlor BA, Craig S. Assessment Scales in Old Age Psychiatry.London: Martin Dunitz.; 1999.h. 33-37.

9. Pudjiastuti SS, Utomo B. Fisioterapi Pada Lansia. Ed 1. Jakarta: Buku Kedokteran EGC; 2003.h. 70-75.

10. Ashendorf L, Jefferson AL, O'Connor MK, Chaisson Christine, Green.RC, Stern RA. Trail Making Test errors in normal aging, mild cognitive impairment, and dementia. Elsevier of Clinical Neuropsychology. 2008;23:129137.

11. Tombaugh TN. Trail Making Test A and B: Normative data stratified by age and education. Pergamon Clinical Neutupsychology. 2004;19;203214. 